\section{Conference dates for your diary}

The British Dental Association (BDA) has confirmed future dates for the British Dental Association Conference and Exhibition:

- 25-27 May 2017

- 10-12 May 2018

- 9-11 May 2019.

The BDA has also announced its intention to hold the conference at the Manchester Central Convention Complex for the next three years.

Dates for next year's event have already been published and have already attracted significant interest.

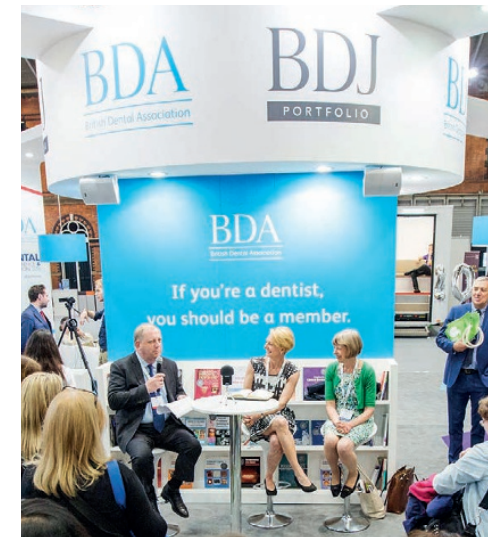

Returning to the North West

from 25 to 27 May, the 2017 conference will aim to build on the success of this year's event which attracted over 4,600 visitors totalling 8,700 separate visits to the trade show and educational activities.

Beyond next year, the conference will move away from the bank holiday weekend and will take place in the early part of May. This change reflects preferences expressed by delegates over the years.

A selection of photos from this year's Conference will be included in the next issue of the $B D J$.

\section{BDA to ensure Brexit works for dentists}

In response to the result of the referendum on membership of the European Union (EU), the British Dental Association (BDA) has pledged to assess and keep its members advised on the full implications of withdrawal from the Union.

Mick Armstrong, Chair of the BDA, said: 'At this early stage we do not know what shape Brexit will take, but it could certainly mean significant changes for both dental regulation and the dental workforce.

'We will aim to ensure withdrawal works for dentists. We will offer support, advice and protect the interests of our membership, and work with our international partners where UK dentists can benefit.'

UK dentistry is affected by EU legislation in a number of areas, including the movement of dentists and dental care professionals, the import of dental equipment and materials, and health and safety legislation. The BDA has been an active member of the Council of European Dentists, and has worked at EU and international level on a wide range of issues like the phase down of dental amalgam.

\section{$B D J$ unveils a new design}

Readers will (hopefully) notice that this issue of the BDJ looks different. We have undertaken a redesign, masterminded by our very capable Production Team Leader, Felicity Agyemang, (to whom many thanks), to refresh and modernise the Journal's look and feel, as well as incorporating new elements such as Research Insights.

This completes a planned phase of redesign for all the publications now in the BDJ Portfolio: BDJ In Practice, BDJ Open, $B D J$ Team and BDJ Student, to give them a consistency and continuity, emphasising the increasingly internationally recognised $B D J$ brand.

In conjunction with this development, and to help celebrate the $B D J$ being the number one dental journal according to Altmetrics (a new and emerging scholarly

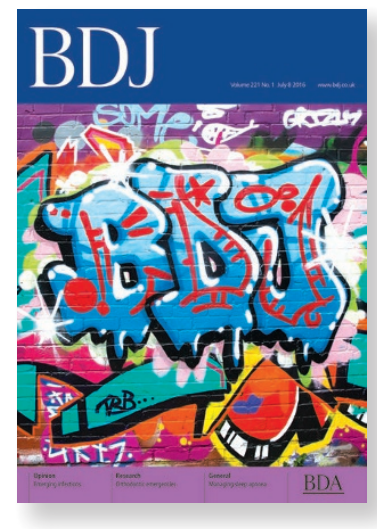
tool which measures online attention of journal articles), the covers for this volume focus on the famous 'BDJ' letters - but not as readers will have seen them before. This issue kicks off the series with a seriously streetwise take on the initials, with other similarly innovative and arresting images to come.

We hope that you like the new look to your journal and we welcome any comments and feedback that you have.

\section{Continued decline in dental academics}

Numbers published in June by the Dental Schools Council indicate a concerning decline in the number of clinical academics on the Research \& Scholarship pathway. Numbers are now at an all-time low of 344 full-time equivalents (FTE) across the UK's 18 publicly funded dental schools. This raises concerns about difficulties in recruitment to these posts and the lack of research experience for trainees coming through the clinical academic pathway.

This is in a context of four new dental schools and expanding student numbers. Many schools have responded creatively to this through an increase in the number of appointments to Teaching \& Scholarship roles. In 2015, these roles number 239 FTE, some 60\% higher than five years ago and now making up $41 \%$ of all clinical academics.

Other key findings of the survey are:

- The majority of funding for dental clinical academic posts is from the four Higher Education Funding Councils (74\%).

- Nearly one third of clinical academic dentists are specialists in restorative dentistry (28\%)

- Half of the clinical academic workforce is aged under 46

- Women make up $41 \%$ of the clinical academic workforce. There are more women lecturers than men (57\%) for the first time, although women remain under represented at Professorial grade (20\%).

The survey can be accessed at: www.dentalschoolscouncil.ac.uk/ wp-content/uploads/2016/06/DSC-survey-2016. 